\title{
Severe hypokalemia and rhabdomyolysis caused by Conn syndrome
}

\author{
(1)Özgür Sirkeci ${ }^{1}$, ĐEmel Erkuş Sirkeci ${ }^{2}$, \Alpaslan Tanoğlu ${ }^{1}$ \\ ${ }^{1}$ Sancaktepe Şehit Prof. Dr. İlhan Varank Training and Research Hospital, Department of Internal Medicine, İstanbul, Turkey \\ ${ }^{2}$ Near East University Hospital Emergency Department, Nicosia, Cyprus
}

Cite this article as: Sirkeci Ö, Erkuş Sirkeci E, Tanoğlu A. Severe hypokalemia and rhabdomyolysis caused by Conn syndrome. J Health Sci Med 2021; 4(1): 103-105.

\begin{abstract}
Hypokalemia is a common electrolyte abnormality. Generally being asymptomatic, muscular fatigue, paresis and arrhythmia can be seen as the severity of hypokalemia increases. Severe rhabdomyolysis and neuromuscular findings can be seen in severe hypokalemia cases. Presence of hypokalemia can be a precursor of secondary hypertension in hypertensive patients, and also should bring hyperaldosteronism into consideration. Mild hypokalemia is usually seen in primary hyperaldosteronism. However, deficient potassium levels are also seen in some cases. We here presented a case of a hypertensive patient, who attended to the emergency department with findings of rhabdomyolysis and neuromuscular findings secondary to severe hypokalemia. The potassium level of our patient was $1.3 \mathrm{mmol}$, and it was one of the lowest potassium levels reported up to today.
\end{abstract}

Keywords: Conn sydrome, hypertension, hypokalemia

\section{INTRODUCTION}

Potassium is a major in-cell cation, and it is one of the most frequently seen electrolyte anomalies. Generally, alongside being asymptomatic, the patient may complain of a lack of strength, muscular pain. Patients with deep hypokalaemia might end up with paraplegia and rhabdomyolysis. Gastrointestinal loss, use of diuretic agents, primary or secondary hyperaldosteronism, hypomagnesemia, Liddle, Bartter and Gitelman syndromes are some of the main reasons of hypokalaemia (1). As hypokalaemia in hypertensive patients can relate to diuretic agents, it can also be related to hyperaldosteronism, which is one of the significant reasons for secondary hypertension. Rarely, hyperaldosteronism can be seen alongside with hypokalaemia and rhabdomyolysis secondary to urinary potassium loss. While evaluating patients, who are assessed regarding hypertension, the first disease which comes to mind on the presence of hypokalaemia should be primary hyperaldosteronism $(\mathrm{PH})$. In these cases, the patient should be checked for plasma aldosterone and plasma renin activity, and plasma aldosterone/plasma renin activity (PA/PRA) ratio should be evaluated. PA/ PRA (ng/dl/dl) $<20$ does not suggest PH. However, if the rate is higher than $30 \%, \mathrm{PH}$ can be considered with $90 \%$ sensitivity and $91 \%$ specificity. If the rate is above
$50 \%$, the possibility of the diagnosis of $\mathrm{PH}$ is much higher $(2,3)$. We here presented a case of a hypertensive patient, who attended to the emergency department with findings of rhabdomyolysis and neuromuscular findings due to severe hypokalemia.

\section{CASE REPORT}

Forty-eight years old female patient presented to the emergency department, with complaints of inability to walk, inability to lift her arms, diffuse myalgia and severe fatigue. The patient stated that especially fatigue and myalgia have worsened in the last 15 days, the myalgia got worse after working in high heels for an extended period the day before, also started to fall during walking and could not move her arms and legs. The patient also stated that she was under follow-up and using valsartan $320 \mathrm{mg}$ $1 \times 1$ and bisoprolol $5 \mathrm{mg} 1 \mathrm{x} 1$ secondary to hypertension for the last four years, and her blood pressure (BP) was still elevated, despite the medication. The patient did not have any additional history; familial history had shown that her mother also had hypertension. Physical examination findings of the patient were; BP was 160/90 $\mathrm{mmHg}$, heart rate was $88 \mathrm{bpm}$. 
Diffuse muscular sensitivity and grade 1/5 muscle strength were noted in upper and lower extremities. On laboratory work-up results: potassium level was $1.3 \mathrm{mmol} / \mathrm{L}$ (3.5$5.5 \mathrm{mmol} / \mathrm{L})$, sodium level was $141 \mathrm{mmol} / \mathrm{L}$ (136-145 $\mathrm{mmol} / \mathrm{L})$, magnesium level was $1.8 \mathrm{mg} / \mathrm{dL}$ (1.6-2.6), urea was $19 \mathrm{mg} / \mathrm{dL}$ (15-40 mg/dL), creatinine was $0.52 \mathrm{mg} / \mathrm{dL}$ (0.57-1.11 mg/dL), aspartat aminotransferase (AST) was $221 \mathrm{U} / \mathrm{L}$ (5-34 U/L), alanine aminotransferase (ALT) was $85 \mathrm{U} / \mathrm{L}$ (0-55 U/L), Ph:7.65, $\mathrm{pCO}_{2}: 34.7 \mathrm{mmHg}, \mathrm{pO}_{2}: 117$ $\mathrm{mmHg}, \mathrm{HCO}_{3}: 40.4 \mathrm{mmol} / \mathrm{L}$, creatine kinase $(\mathrm{CK})$ was $14248 \mathrm{U} / \mathrm{L}(\leq 145 \mathrm{U} / \mathrm{L})), 24$ hour urine potassium was $98 \mathrm{mmol} / 24 \mathrm{~h}(25-125 \mathrm{mmol} / 24 \mathrm{~h}), \mathrm{TSH}$ was $1.513 \mathrm{IU} /$ $\mathrm{mL}(0.4-4.9 \mathrm{IU} / \mathrm{ml})$, free T4 was $0.99 \mathrm{ng} / \mathrm{dL}(0.6-1 \mathrm{ng} /$ $\mathrm{dl})$, cortisol was $15.1 \mathrm{ug} / \mathrm{dL}$ (5-20 ug/dl). The patient had deep hypokalaemia, metabolic alkalosis, elevated AST, ALT and significantly elevated CK levels. The cause of neuromuscular symptoms was related to hypokalaemia and rhabdomyolysis secondary to hypokalaemia. The patient was started on fluid and $120 \mathrm{mmol} /$ day potassium replacement treatment. Starting from the second day of treatment, potassium level was noted as $2.2 \mathrm{mmol} /$ $\mathrm{mL}$ and neuromuscular complaints started to normalise. During this process, as combined hypokalaemia and HT, hyperaldosteronism and Liddle syndrome were considered, plasma aldosterone, plasma renin activity, urinary sodium and potassium levels were evaluated. Elevated urinary potassium and normal sodium levels were found. No significant finding, consistent with renal artery stenosis was noted on renal doppler USG. Abdominal MRI was planned, as the patient had a severe elevation of aldosterone $(887 \mathrm{pg} / \mathrm{mL})$, plasma renin activity $(0.27$ $\mathrm{ng} / \mathrm{mL}), \mathrm{PA} / \mathrm{PRA}$ level was $(328.5 \mathrm{ng} / \mathrm{ml})$ pointed to the presence of an aldosterone synthesis related adrenal mass lesion. A well-circumscribed lesion, measuring 33×20 mm in size, which appeared homogeneous hyperintense on T1-Weighted sequences and heterogenous hyperintense appearance on T2-Weighted sequences. Located in the superior segment of the right adrenal gland, was noted on Abdominal MRI. The lesion showed contrast uptake on post-contrast slices, and no significant wash-out was seen in late phases. The current findings were primarily considered in favour of adenoma (Figure). The presence of hypokalaemia and HT combination, elevated plasma Aldosterone level, PR/PRA elevation and unilateral adrenal adenoma led to the diagnosis of Conn Syndrome. The potassium level of the patient was elevated up to 3.3 $\mathrm{mmol} / \mathrm{mL}$ with replacement, and the CK levels returned to normal. Neuromuscular complaints recovered and the patient was discharged with spironolactone treatment at the dose of $100 \mathrm{mg}$. On the follow-up after one week the findings were noted as; $\mathrm{K}: 3.4 \mathrm{mmol} / \mathrm{mL}$, Blood pressure with only spironolactone: $125 / 80 \mathrm{mmHg}$. The patient had been referred to surgery secondary to unilateral adenoma, which causes aldosterone synthesis. Written informed consent was obtained from the patient.

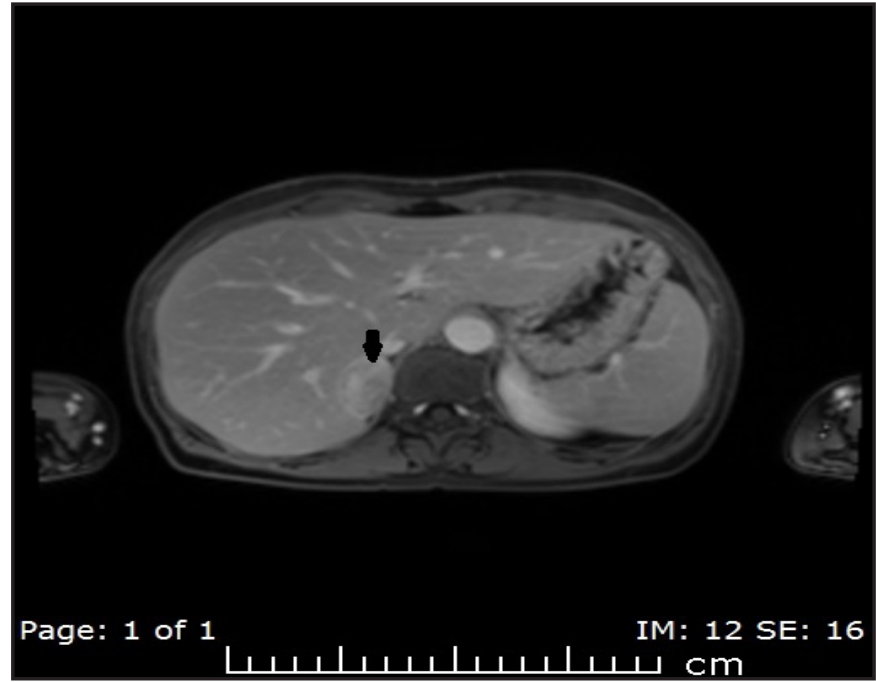

Figure. Contrast enhanced abdominal computerized tomography: arrow indicated surrenal adenoma.

\section{DISCUSSION}

Hypokalemia is one of the common findings of Conn syndrome. However, hypokalemia may not be present in all cases if present usually mild hypokalemia can be seen, rarely presents with severe hypokalemia (4). In the case of Yandle et al. (5) the patient's potassium level was 1.5 $\mathrm{mmol} / \mathrm{L}$ but the patient was asymptomatic. Hypokalemia is a common finding in emergency departments and the main causes of hypokalemia are malnutrition and use of diuretics (6). But if hypertensive patients is presenting with hypokalemia other rare conditions should be considered.

Hypokalemic patients usually present with complaints of myalgia, and chronic hypokalaemia is often well tolerated, and patients may not have significant complaints. However, rhabdomyolysis risk increases when potassium levels drop below $2 \mathrm{mmol} / \mathrm{mL}$ (7). Our patient also had a significant increase of complaints within the last 15 days, and excessive work the day before had increased the severity of muscular damage and, the patient has presented to the Emergency department with primary secondary to neuromuscular symptoms. In two cases reported by Wen et al. (8) potassium levels were 1.38 and $1.98 \mathrm{mmol} / \mathrm{ml}$. Patients were admitted with neuromuscular symptoms as in our case. Even though the elevation of potassium levels was expected due to rhabdomyolysis, potassium levels were noted at a deficient level as $1.3 \mathrm{mmol} / \mathrm{ml}$. To the best of our knowledge this is one of the lowest potassium level reported up to today. This condition was considered as related to the potassium-exerting effect of aldosterone. Urinary potassium level was also high. The presence of combined HT, hypokalaemia and metabolic alkalosis brought hyperaldosteronism and Liddle Syndrome in mind. Due to this reason, plasma aldosterone and 
plasma renin levels and urinary sodium levels were checked. Urinary sodium levels were within the normal range, but aldosterone levels were severely elevated. As the PA/PRA ratio was $>50$, it brought primary hyperaldosteronism into consideration. Because this level of PA/PRA indicates Conn syndrome (9). Also, the MRI findings, which shown unilateral adenoma, was a significant fact to support our diagnosis. Dramatical recovery was noted following fluid and potassium replacement and the patient, who presented in tetraplegic state started to walk without aid on the third day. CK levels returned to normal on the sixth day, and potassium level was brought up to $3.4 \mathrm{mmol} / \mathrm{ml}$. On the background evaluation of the patients' old test results, the potassium level of the patient, when diagnosed with $\mathrm{HT}$, was $3.3 \mathrm{mmol} / \mathrm{mL}$. It was considered as a detail which was unnoticed during the evaluation of secondary HT. Especially the presence of hypokalaemia is a significant factor during the aetiology of hypertension, and it should bring Conn Syndrome into consideration. The patient started to be in a normotensive state with spironolactone at the dose of $100 \mathrm{mg} 1 \mathrm{x} 1$, when not under control of the dual anti-hypertensive agent.

\section{CONCLUSION}

Hypokalaemia is an electrolyte abnormality which has fatal complications. Patients, who present to the emergency department with complaints of myasthenia, myalgia and neuromuscular symptoms should be primarily evaluated for this matter. The presence of hypokalemia should be considered after ruling out the factors such as vomiting, diarrhoea and use of diuretics in hypertensive patients.

\section{ETHICAL DECLARATIONS}

Informed Consent: Written informed consent was obtained from all participants who participated in this study.

Referee Evaluation Process: Externally peerreviewed.

Conflict of Interest Statement: The authors have no conflicts of interest to declare.

Financial Disclosure: The authors declared that this study has received no financial support.

Author Contributions: All of the authors declare that they have all participated in the design, execution, and analysis of the paper, and that they have approved the final version.

\section{REFERENCES}

1. Vilela LAP, Almeida MQ.Diagnosis and management of primary aldosteronism. Arch Endocrinol Metab 2017; 61: 305-12.

2. Morimoto R, Omata K, Ito S, Satoh F. Progress in the Management of Primary Aldosteronism. Am J Hypertens 2018 13; 31: 522-31.

3. Tun HN. Severe Hypokalemia with premature ventricular contraction. EC Cardiology 5.4 2018: 224-8.

4. Buffolo F, Monticone S, Burrello J, et al. Is Primary Aldosteronism Still Largely Unrecognized? Horm Metab Res 2017; 49: 908-14.

5. Yandle G, Vonderhaar DJ, Thayalakulasingam T, et al. Clinical case of the month: persistent hypertension in a young woman: a classic presentation of Conn's syndrome. J La State Med Soc 2016; 168: 23-6.

6. Marti G, Schwarz C, Leichtle AB, et al. Etiology and symptoms of severe hypokalemia in emergency department patients. Eur J Emerg Med 2014; 21: 46-51.

7. Williams TA, Reincke M. Management of endocrine disease: diagnosis and management of primary aldosteronism: the Endocrine Society guideline 2016 revisited. Eur J Endocrinol. 2018; 179: R19-R29.

8. Wen Z, Chuanwei L, Chunyu Z, Hui H. Rhabdomyolysis presenting with severe hypokalemia in hypertensive patients: a case series. BMC Res Notes 2013; 6: 155.

9. Lee FT, Elaraj D. Evaluation and Management of Primary Hyperaldosteronism. Surg Clin North Am 2019; 99: 731-45. 